\title{
CULTURAL DIFFERENCES IN OPPORTUNITY COST CONSIDERATION
}

\author{
By
}

Ning Zhang

\begin{abstract}
A thesis submitted to the Department of Psychology
in conformity with the requirements for

the degree of Master of Science
\end{abstract}

Queen's University

Kingston, Ontario, Canada

July 2013

Copyright (C) Ning Zhang, 2013 


\begin{abstract}
I conducted two studies to explore cultural differences between Chinese and European Canadians in considering opportunity cost while making purchase decisions. In Study 1, participants (121 Euro-Canadians and 119 Chinese) read a scenario in which they would decide whether to buy a single product (e.g., a backpack) or not. Participants were randomly assigned to either a condition in which opportunity cost information was made salient or a control condition in which opportunity cost was not mentioned. I found that participants in the opportunity cost salient condition displayed a higher level of opportunity cost consideration than did participants in the control condition. When individual differences in the habit of considering opportunity cost and spending habits were controlled for, Chinese participants' purchase decisions revealed a higher degree of opportunity cost consideration than those of European Canadians. Chinese were also more likely to mention opportunity cost thoughts than did European Canadians while making the decision. In Study 2, participants chose one of two laptops to buy (one was cheaper but had less memory than the other). The results demonstrated that Chinese living in Canada displayed a higher degree of opportunity cost consideration by opting more often for the cheaper laptop, than did European Canadians. However, the culture main effect was confounded by cultural differences in family income. Study 2 also replicated the results of Study 1 that Chinese were also more likely to mention opportunity cost thoughts than European Canadians while making the decision. Although inconclusive, these results suggest that opportunity cost consideration varies, at least to some extent, across cultures. Implications of the current research for consumer behavior and directions for future research are discussed.
\end{abstract}




\section{Acknowledgement}

I like to express my appreciation to all the warm-hearts for lending their hands to me at different stages of this project. Firstly, I am very grateful to my supervisor, Dr. Li-Jun Ji, for her encouragement, patience, and detail-oriented guidance during the process for this project from the beginning to the end. Secondly, I'd like to express my sincere gratitude towards Dr. Leandre Fabrigar and Dr. Jill Jacobson for serving on my thesis committee. Your comments and suggestions challenged me to refine my statistical analysis skills, which would be one of the great assets I could acquire during my graduate study here at Queen's. Thanks also go to Dr. Ye Li from Huazhong Normal University for helping with data collection for Chinese participants in Study 1. I would also like to thank Albert Lee for his constructive comments for this project and Kayla McGeorge, Sarah Cabecinha-Alati, Kelly Huang, Siyan Jing, Melissa Lucas, Stella Moon for their help on many aspects of this project. I am also indebted to my parents, brother, sister, and friends for their unconditional support from the other side of the globe. 


\section{Table of Contents}

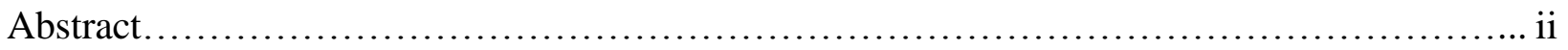

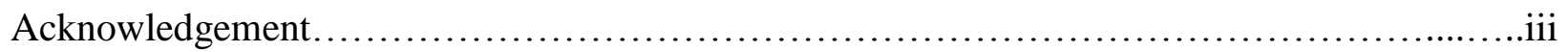

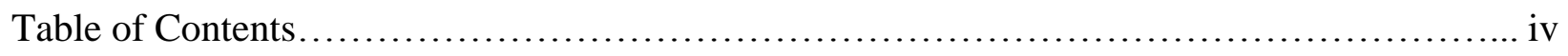

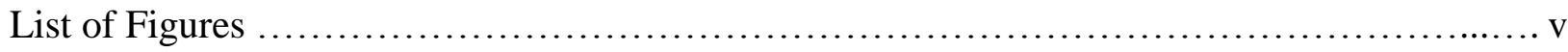

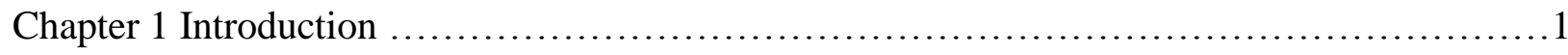

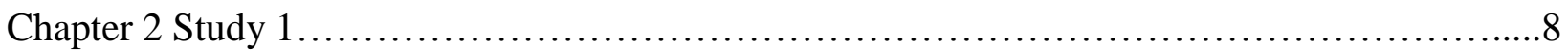

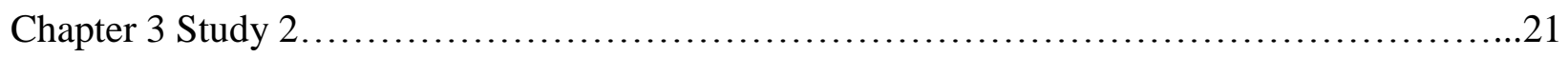

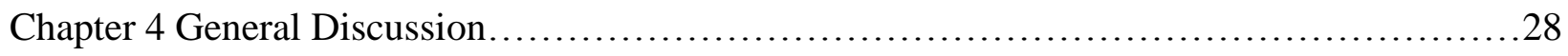

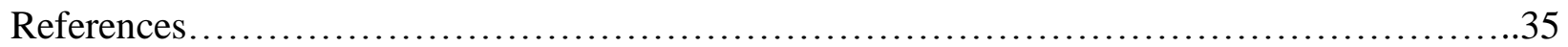

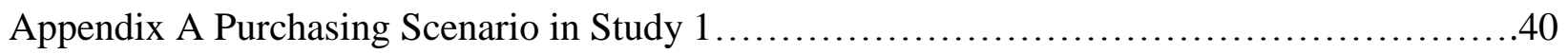

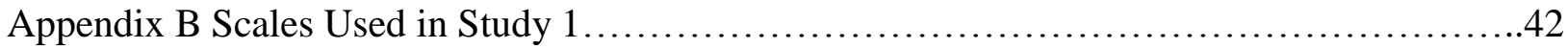

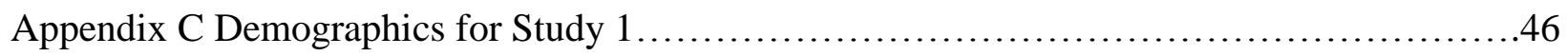

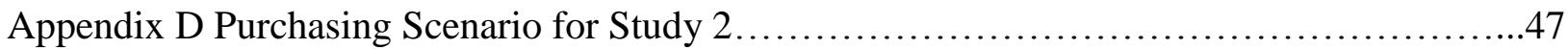

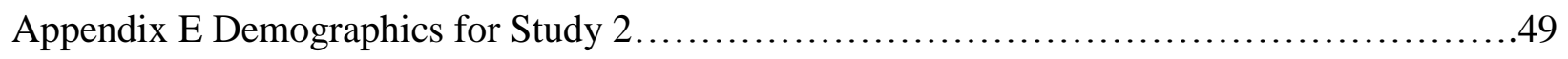

Appendix F Letter of Information \& Consent Form.....................................50

Appendix G Debriefing letter....................................................... 51

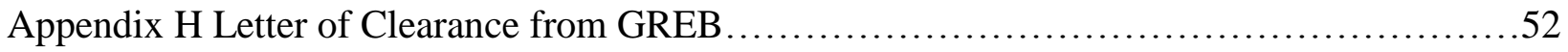




\section{List of Figures}

Figure 1. Differences in Likelihood of Choosing not to buy the Backpack as a Fuction of Culture

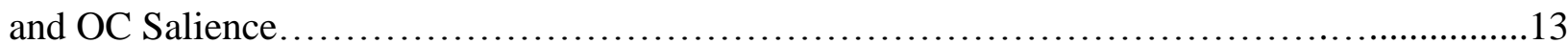

Figure 2. Relationship between choice and condition, depending on $\mathrm{OCC}, \mathrm{OCC}=$ opportunity

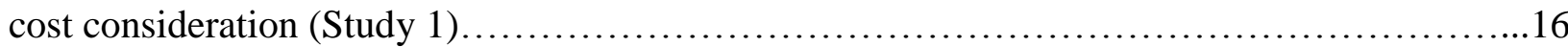

Figure 3. Relationship between choice and condition, depending on Culture and STS, STS =

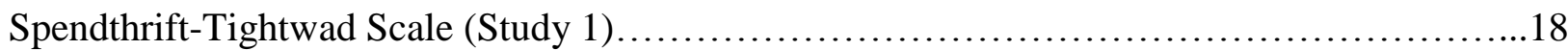
Figure 4. Differences in the Likelihood of Choosing the Cheaper Laptop as a Function of Culture and OC Salience. 


\section{Chapter 1: Introduction}

Will you choose to buy a luxury stereo system with your $\$ 2,000$ holiday bonus or spend the money for a wonderful holiday at a Caribbean island resort? Are you going to spend Sunday afternoon hanging out with your friends or spending time with your family? Are you going to accept a job offer from a Fortune 500 company involving a move to another city every other year or an offer from a government agency that offers great stability? As easy of a decision as each of these examples seems to be at first glance, you may hesitate to make one choice and give up the alternatives. In other words, your final decision depends on how you weigh the opportunity cost of your choice.

Originally an economic term, opportunity cost is typically defined as "benefits foregone as a result of rejecting the next best alternative action" (Becker, Ronen, \& Sorter, 1974, p. 317). With its high relevance for judgment and decision-making, the concept of opportunity cost has drawn substantial attention from researchers in accounting, behavioral economics, and marketing since the 1970s (Frederick, Novemsky, Wang, Dhar, \& Nowlis, 2009; Friedman \& Neumann, 1980; Neumann \& Friedman, 1978; Northcraft \& Neale, 1986). The present paper examines possible cross-cultural differences in the extent to which people consider opportunity cost in making purchase decisions. I first review previous research documenting the "opportunity cost neglect" phenomenon and then discuss how opportunity cost neglect or consideration may vary across cultures.

\section{Opportunity Cost Neglect}

According to classic economic theory, people should think and behave rationally to maximize their benefits and minimize losses, but research in behavioral economics and psychology has frequently demonstrated that this is not always the case. Instead, "irrationality" is commonly found in human judgments and decision-making behaviors (Ariely, 2008; Thaler, 
1980). Rationally speaking, people should consider opportunity cost (i.e., the alternative returns one has to give up) in every judgment and decision they make to maximize the returns. However, empirical evidence has demonstrated that people rarely take opportunity cost into consideration in decision-making if information about opportunity cost is not explicitly presented (Frederick et al., 2009; Northcraft \& Neale, 1986; Shavit, Rosenboim, \& Malul, 2011).

For instance, Northcraft and Neale (1986) documented that, compared to situations in which information about opportunity cost was not mentioned, explicitly presenting opportunity cost information prompted people to alter their decisions to be congruent with the traditional cost/benefit analysis paradigm proposed by economists. In other words, opportunity cost information was more likely to be taken into account in decision-making when it was explicitly provided than not. This phenomenon was recently documented by Frederick et al. (2009) in purchase decision-making. For example, in one study, half of the participants chose between the options "Buy this entertainment video" and "Not buy this entertainment video" (control condition); the other half of the participants chose between "Buy this entertainment video" and "Keep the money for other purchases" (opportunity cost salient condition). They found that participants in the control condition were more likely to buy the entertainment video than were participants in the opportunity cost salient condition, suggesting that people were less likely to consider opportunity cost (and therefore purchased the video) when the opportunity cost information was not salient.

\section{Causes for Opportunity Cost Neglect/Consideration}

Why do people neglect opportunity costs in making decisions? Researchers from multiple disciplines have attempted to address this question for the past several decades. The explanations include focusing bias in judgment and decision-making (Legrenzi, Girotto, \& 
JohnsonLaird, 1993), resource constraints (Spiller, 2011), and individual differences, such as propensity to plan for money and spending habits (Frederick et al., 2009; Spiller, 2011). I will discuss each of these explanations in the following sections.

Focusing Bias in Judgment and Decision-making. One potential cause of "opportunity cost neglect" is focusing bias in judgment and decision-making. Legrenzi et al. (1993) have shown that people are more likely to focus on the information explicitly presented in various reasoning and decision-making tasks. They suggest that focusing on explicit information leads people to neglect alternative options in reasoning and decision making. Thus, providing contextual information should reduce focusing bias and prompt people to consider other choices in decision-making. In support of this prediction, they found that when deciding to engage in a certain activity in a foreign city (e.g., go to a movie, attend a sporting event), participants in the context group (in which information about other options were presented) were more likely to ask questions about alternative options than were participants in the control condition (in which information about alternative options were not presented).

In line with this finding, consumer behavior researchers have documented the brand positivity effect (Posavac, Sanbonmatsu, Kardes, \& Fitzsimons, 2004; Posavac, Kardes, Sanbonmatsu, \& Fitzsimons, 2005), such that people evaluate a single brand more favorably if it is presented in isolation than presented with other brand options. In a set of experiments, Posavac et al. $(2004,2005)$ documented that the brand positivity effect resulted from selective information processing of the focal brand. In other words, people typically base their evaluation on the information presented about the focal brand without considering information about other brands. In a similar vein, research has demonstrated that subtle differences in framing options as either opportunities (i.e., whether or not to buy a new $\mathrm{CD}$ ) or choices (i.e., whether to buy a new 
CD or something else) significantly influence people's preferences (Jones, Frisch, Yurak, \& Kim, 1998). Specifically, they found that framing options as opportunities led to a higher probability of choosing the target option (i.e., buy the new $\mathrm{CD}$ ), whereas framing options as choices increased the probability of choosing other alternatives. The results are likely accounted for by the focusing mechanism such that participants focus their attention on the target option in the opportunity framing condition but divide their attention between the target option and other alternative options in the choice framing condition.

Resource Constraints. Another factor pertinent to opportunity cost consideration is the perceived constraint of resources by decision-makers. That is, the more resource constraints people perceive, the more they should consider opportunity cost in decision-making. In a single lab session, Spiller (2011) simulated a series of 20 purchases, one each weekday for four weeks. He assigned participants either to a weekly payment condition (i.e., they received $\$ 20$ store credit each Monday for four weeks, resulting in more constraints) or monthly payment condition (i.e., they received $\$ 80$ store credit on the first Monday, resulting in less constraint). Participants were instructed that, before making the purchase decision each day, they could consider the next three days' offers, and money spent on one day would not be available for future days. Opportunity cost consideration was measured as the proportion of future opportunities considered in making the daily shopping decisions. He found that participants in the weekly payment condition were more likely to consider opportunity cost than were people in the monthly payment condition. Additionally, perceived resource constraint mediated the relationship between payment condition and level of opportunity cost consideration such that, compared to monthly paid participants, weekly paid participants perceived greater resource constraint, which in turn led to greater consideration of opportunity cost. 
Likewise, Zauberman and Lynch (2005) demonstrated that perceived abundance in certain resources affects temporal discounting of future investments of those resources. More specifically, when people perceived that they would have more available time than money in the future, they were more likely to discount future investment of time (e.g., making a lot of future commitments that one would not accept if being asked now) than money. In other words, expected abundance of future time made people less likely to consider opportunity cost in making time-allocating decisions for future tasks. The trend was reversed when people perceived to have more money than time available in the future. The results indicate that perceived resource constraints influence people's consideration of opportunity cost in decisionmaking.

Individual Differences. Research has shown that individual differences also moderate the extent to which people consider opportunity costs (Frederick et al., 2009; Spiller, 2011). For example, in one study, Frederick et al. (2009) found that tightwads were more likely to consider opportunity cost chronically and therefore were less influenced by the salience of opportunity cost information than were spendthrifts. In another study, Spiller (2011) found that, in the absence of resource constraints, planners were more likely to consider opportunity costs than were nonplanners. Accordingly, resource constraints significantly increased the level of opportunity cost consideration among nonplanners but not among planners, as planners were generally more likely to consider opportunity cost already and thus were less susceptible to the resource constraint manipulation. These results highlight the importance of including individual difference variables in research about opportunity cost consideration.

\section{Culture}


Most of the research on opportunity cost consideration has been conducted in North America with participants of European descent (Frederick et al., 2009; Northcraft \& Neale, 1986; Spiller, 2011; Vera-Muñoz, 1998), so little is known about whether and how it would vary across cultures. Based on previous research on culture and cognition, particularly, cultural differences in context sensitivity (Heine, 2010; Nisbett, Peng, Choi, \& Norenzayan, 2001; Nisbett \& Norenzayan, 2002; Nisbett, 2003), I predicted that East Asians would exhibit less opportunity cost neglect than would European North Americans.

East Asians are generally more sensitive and attentive to context than are North Americans (Ji, Peng, \& Nisbett, 2000; Masuda \& Nisbett, 2001; Masuda, Gonzalez, Kwan, \& Nisbett, 2008; Nisbett et al., 2001; Nisbett \& Norenzayan, 2002; Nisbett, 2003). For example, Ji et al. (2000) found that, compared to European Americans, East Asians were more likely to detect covariation between events and were more field dependent when making perceptual judgments. Similarly, Masuda and Nisbett (2001) found that, compared with Americans, Japanese recalled more information about contexts and relationships and were more likely to recognize an object when it was presented in its original setting instead of a novel setting.

In everyday life, people frequently face decisions that involve choosing one option among multiple alternatives. The nonfocal alternatives can be considered as the context for decision-making. In most situations, however, alternative options are not explicitly presented. Given that East Asians are more sensitive to contexts than are European North Americans, would they also be more readily attentive to alternative options and therefore more likely to consider opportunity cost while making decisions? This is the question to be addressed in the present research. If it is indeed the case, East Asians should display a higher degree of opportunity cost consideration than should European North Americans. Accordingly, if East Asians are more 
likely to take opportunity cost into account spontaneously, they would be less susceptible to the influence of the opportunity cost information that is explicitly provided and therefore benefit less from it than European North Americans.

\section{Overview of the Current Research}

Based on previous research on opportunity cost neglect and on cultural differences in sensitivity to context, I proposed that European Canadians and Chinese would differ in their level of opportunity cost consideration in purchase decision-making. Specifically, I had the following hypotheses:

H1: European Canadians would display a lower degree of opportunity cost consideration than would Chinese, especially when opportunity cost information is not explicitly mentioned or primed.

$\mathrm{H} 2$ : The salience of opportunity cost information would significantly increase European Canadian participants' consideration of opportunity cost, compared to the control condition, whereas the salience of opportunity cost information would have a weaker or no effect on Chinese participants' opportunity cost consideration.

Two studies were conducted to test the above hypotheses. Study 1 examined how the salience of the opportunity cost information (manipulated through the wording of one of the choice options) influenced participants' likelihood of choosing to buy a product and whether the effect would be moderated by individual difference variables pertinent to opportunity cost consideration. Study 2 explored if priming opportunity cost would have different effects on European Canadian and Chinese participants' intention to purchase the cheaper option of two similar products. 


\section{Chapter 2: Study 1}

The purpose of Study 1 was to examine if manipulating the salience of opportunity cost information would have divergent effects on opportunity cost consideration and on the purchase decisions of European Canadians and Chinese. Study 1 also explored the potential moderating effects of individual difference variables, including habits of considering opportunity cost, propensity to plan for money, and spending habits, as previous research has shown their relevance to opportunity cost consideration (Frederick et al., 2009; Spiller, 2011).

\section{Method}

\section{Participants}

One hundred and twenty-one European Canadian students at Queen's University (100 women, 21 men; $M_{\text {age }}=18.17$ years, $\left.S D=.96\right)$ and 119 Chinese university students at Huazhong Normal University, China ( 86 women, 33 men; $M_{\text {age }}=19.51$ years, $S D=.86$ ) participated in Study 1. European Canadian participants received course credit for their participation; Chinese participants received small gifts as a compensation for their participation.

Materials (see Appendix B for more details)

Opportunity Cost Consideration Scale (OCC; Spiller, 2011). This 3-item scale measures habits of considering opportunity cost. A sample item is "I often think about the fact that spending money on one purchase now means not spending money on some other purchase later." The reliability of the OCC in the original study was .85. The standardized Cronbach's alpha for this scale was .82 for Canadians and .76 for Chinese in the current study. Following previous research, a mean score was calculated based on participants' responses to the three items, with higher scores indicating a stronger habit of considering opportunity cost in making purchase decisions (Spiller, 2011). 
Propensity to Plan for Money Scale-Long Term (PPM; Lynch, Netemeyer, Spiller, \& Zammit, 2010). The 6-item scale assesses individual differences in the propensity to plan for spending money in the long run. A sample item is "I set financial goals for the next 1-2 years for what I want to achieve with my money." The original reliability of the PPM was .69. The standardized Cronbach's alpha for this scale was .90 for European Canadian participants and .87 for Chinese participants in this study. In line with previous research, a mean score was calculated based on participants' responses to the six items, with higher scores indicating a stronger propensity to plan for how to spend money (Lynch et al., 2010).

Spendthrift-Tightwad Scale (STS; Rick, Cryder, \& Loewenstein, 2008). This scale has four items to measure individual differences in spending habits. Participants were asked to describe to what extent they experience difficulty in spending money or controlling their spending. The scale's original reliability was .75. The standardized Cronbach's alpha for this scale was .84 and .69 for European Canadians and Chinese participants, respectively, in the current study. Consistent with previous research, after reverse coding two of the questions, a sum score was calculated as a measure of participants' spending habit, with higher scores representing spendthrifts and lower scores representing tightwads (Rick et al., 2008). ${ }^{1}$

\section{Procedure}

Participants read a decision-making scenario adapted from Frederick et al. (2009). In the scenario, participants imagine that they have been saving some extra money to make some purchases. On their most recent visit to a shopping mall, they came across a special sale on a

\footnotetext{
${ }^{1}$ Exploratory factor analysis using Principal Axis Factoring extraction with Direct oblimin rotation for the Opportunity Cost Consideration, Propensity to Plan for Money-Long Term, and Spendthrift-Tightwad scales revealed that all items loaded highly onto the proposed single factors for each of the scales across the two cultural samples.
} 
new travel backpack (\$29.99), which happened to be their favorite style. Participants were randomly assigned to the control condition or opportunity cost salient condition. Participants in the control condition read two options: "Buy this backpack" (option A) or "Not buy this backpack" (option B); participants in the opportunity cost salient condition read: "Buy this backpack" (option A) or "Keep the $\$ 29.99$ for other purchases" (option B). Thus the only difference between the two conditions was how option B was phrased. By bringing up other potential purchases, the wording in the opportunity cost salient condition should have highlighted the opportunity costs of buying the backpack. Following Frederick et al. (2009), choosing not to buy the backpack was considered as a decision consistent with opportunity cost consideration. The study material was created in English and translated into Chinese. Following conventions used in behavioral economics, the price of the backpack was converted into Chinese yuan based on the Big Mac Index (2012).

Participants indicated their likelihood of choosing option A or B on an 8-point bipolar scale $(l=$ definitely choose option A, $8=$ definitely choose option B). They also listed any thoughts they had when deciding which option to choose. The order of choice rating and thoughts listing was counterbalanced among participants. ${ }^{2}$ Next, participants indicated the amount of money they imagined they had saved and how their choice would influence their ability to buy other things (see Appendix A for details). They then completed the OCC, PPM, and STS scales (see Appendix B for details).

Finally, participants reported demographic information, including age, gender, ethnicity, amount of pocket money they typically have for each month, family income, mother's education

\footnotetext{
${ }^{2}$ Data analysis showed no order effect; therefore, it will not be discussed further.
} 
level, father's education level, and their perceived level of financial security (see Appendix C for details).

\section{Results}

\section{Presence of Opportunity Cost Thoughts}

Four research assistants blind to the hypothesis coded the thoughts participants listed. They coded whether or not participants mentioned opportunity cost (e.g., other items they planned to buy) in making the decision. Two Canadian research assistants coded the Canadian participants' thoughts, inter-coder agreement was 94\%; two English-Chinese bilingual assistants coded the Chinese participants' thoughts; inter-coder agreement was 92\%. Disagreements between coders were resolved through discussion.

First, I conducted a binary logistic regression to examine how presence of opportunity cost consideration thoughts $(0=$ not considering opportunity cost, $1=$ considering opportunity cost) could be predicted by culture, condition, centered OCC, and all the two-way and three-way interactions. The overall model with the simultaneous entering method was significant, $\chi^{2}(7)=$ $25.15, p=.001$, Nagelkerke $\mathrm{R}^{2}=.15$. Culture, condition, and OCC were all significant predictors of the presence of opportunity cost thoughts. Chinese were 2.52 times more likely to mention opportunity cost thoughts than were European Canadians, $W^{2}(1)=6.08, p=.01$. Participants in the opportunity cost salient condition were 2.45 times more likely to mention opportunity cost thoughts than were participants in the control condition, $W^{2}(1)=5.71, p=.02$. The odds of mentioning opportunity cost thoughts were 1.55 times greater for every one unit increase in participants' OCC scores, $W^{2}(1)=11.39, p=.001$. No other effects were significant, $\exp (B) s<$ $1.21, W^{2}(1) \mathrm{s}<2.05, p s>.15$. 
Second, I conducted a binary logistic regression to examine how presence of opportunity cost consideration thoughts $(0=$ not considering opportunity cost, $1=$ considering opportunity cost) could be predicted by culture, condition, centered PPM, and all the two-way and three-way interactions. The overall model with the simultaneous entering method was significant, $\chi^{2}(7)=$ $14.51, p=.04$, Nagelkerke $\mathrm{R}^{2}=.09$. Culture, condition, and PPM were all significant predictors of the presence of opportunity cost thoughts. Chinese were 1.95 times more likely to mention opportunity cost thoughts than were European Canadians, $W^{2}(1)=3.72, p=.05$. Participants in the opportunity cost salient condition were 2.42 times more likely to mention opportunity cost thoughts than were participants in the control condition, $W^{2}(1)=6.53, p=.01$. The odds of mentioning opportunity cost thoughts were 1.30 times greater for every one unit increase in participants' PPM scores, $W^{2}(1)=4.92, p=.03$. No other effects were significant, $\exp (B)_{s}<$ $1.12, W^{2}(1) \mathrm{s}<.75$, ps $>.38$.

Finally, I conducted a binary logistic regression to examine how presence of opportunity cost consideration thoughts $(0=$ not considering opportunity cost, $1=$ considering opportunity cost) could be predicted by culture, condition, centered STS, and all the two-way and three-way interactions. The overall model with the simultaneous entering method was marginally significant, $\chi^{2}(7)=12.87, p=.08$, Nagelkerke $\mathrm{R}^{2}=.08$. Participants in the opportunity cost salient condition were 2.17 times more likely to mention opportunity cost thoughts than were participants in the control condition, $W^{2}(1)=5.91, p=.02$. No other effects were significant, $\exp (B) s<1.54, W^{2}(1) \mathrm{s}<1.95, p s>.16$.

\section{Likelihood of Not Buying the Backpack}

I conducted a two-way ANOVA with culture (European Canadian vs. Chinese) and condition (Opportunity cost salient vs. Control) as independent variables and the likelihood of 
choosing not to buy the backpack as the dependent variable. The culture main effect was not significant, $F(1,235)=0.88, p=.35$, However, the condition main effect was significant, $F(1$, $235)=5.78, p=.02, \eta_{\mathrm{p}}^{2}=.02$. Participants in the opportunity cost salience condition $(M=2.97$, $S D=1.90)$ were less likely to buy the backpack than were participants in the control condition $(M=2.42, S D=1.60)$. The condition main effect seems to be driven more by European Canadians. As can be seen in Figure 1, European Canadians were less likely to buy the backpack in the opportunity cost salient condition than in the control condition, $F(1,235)=5.16$, $p=.02$, suggesting greater consideration of opportunity cost in the former than latter conditions. On the other hand, Chinese participants' choices did not differ significantly between the two conditions, $F(1,235)=1.29, p=.26$. Unfortunately, the interaction between culture and condition was not significant, $F(1,235)=0.62, p=.43$.

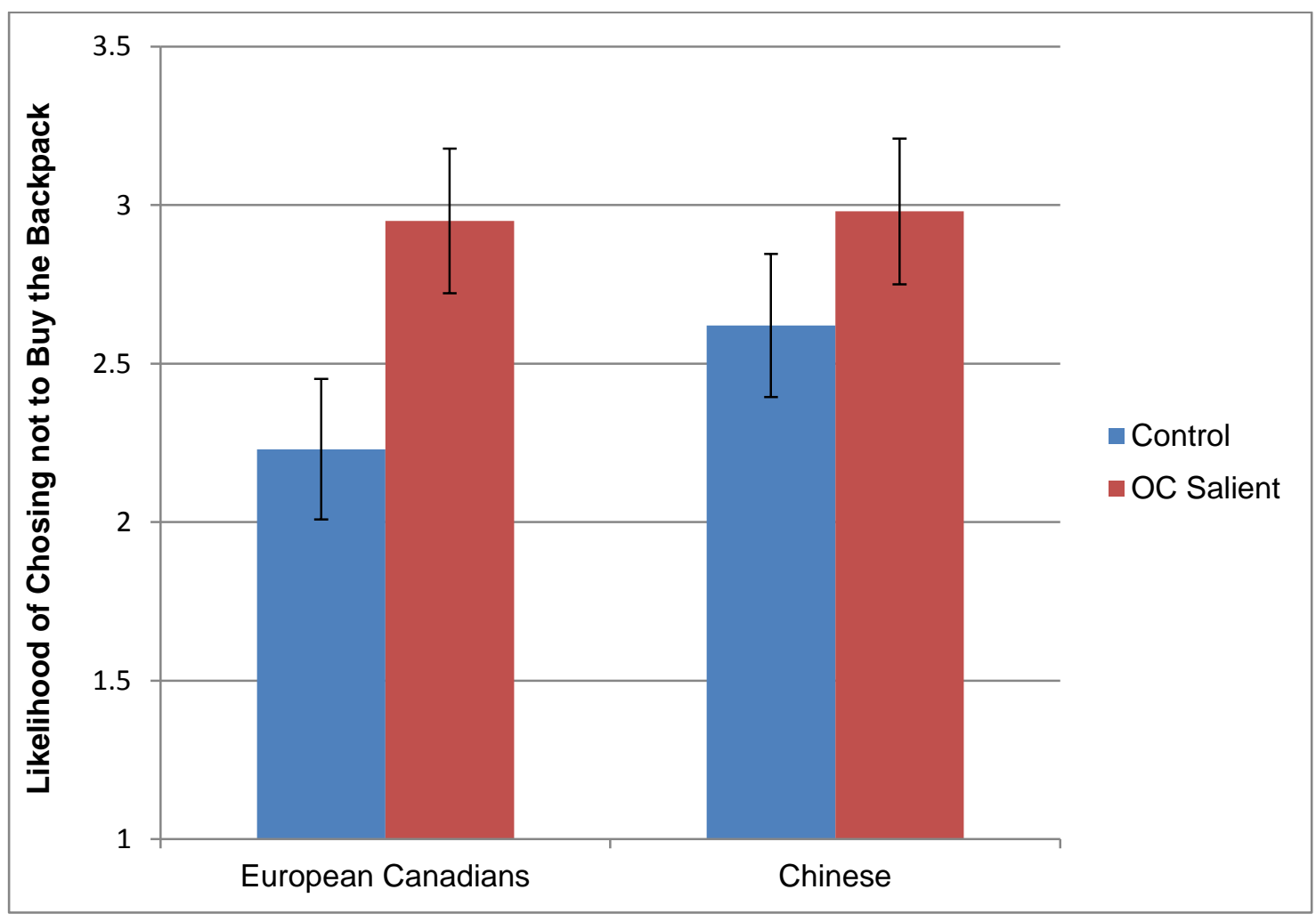


Figure 1. Differences in Likelihood of Choosing Not to Buy the Backpack as a Function of Culture and OC Salience

\section{Moderation effects of Individual Difference Variables on Choice}

Comparison between European Canadians and Chinese on the individual difference variables indicated that European Canadians $(M=5.01, S D=1.32)$ reported a stronger habit of considering opportunity cost than did Chinese $(M=3.98, S D=1.48), t(238)=5.74, p<.001$. Similarly, European Canadians $(M=4.43, S D=1.44)$ reported a significantly higher propensity to plan for money than did Chinese $(M=3.22, S D=1.25), t(238)=6.97, p<.001$. Meanwhile, Chinese $(M=15.92, S D=3.61)$ scored higher on the STS scale than European Canadians $(M=$ $14.59, S D=4.58), t(235)=2.48, p=.01$.

I conducted a series of moderated regression analyses to explore how the effects of culture and condition on choice were moderated by participants' habits of considering opportunity cost (OCC), propensity to plan for money (PPM), and spending habits indexed by their scores on the spendthrift- tightwad continuum (STS). To reduce multicollinnearity, I centered all continuous predictors (OCC average, PPM average, and STS total) and did effect coding for the two categorical variables - culture ( 1 = European Canadians, $-1=$ Chinese $)$ and condition $(1=$ control, -1 = opportunity cost salient $)$.

First, I explored if the habit of opportunity cost consideration (OCC) moderated the effects of culture and condition on choice by regressing choice on effects coded culture, effects coded condition, centered OCC, and all the 2-way and 3-way interactions. The overall model was significant, $F(7,231)=4.09, p=.001$. The results revealed that culture, $B=-.25, t(231)=$ $2.09, p=.04$, condition, $B=-.33, t(231)=2.75, p=.006$, and OCC, $B=.20, t(231)=2.47, p$ $=.01$, were all significant predictors of choice. These main effects indicated that Chinese were 
less likely to buy the backpack than were European Canadians; participants in the opportunity cost salient condition were less likely to choose to buy the backpack than did participants in the control condition; the stronger participants' habit of considering opportunity cost, the less likely they chose to buy the backpack. However, the condition and OCC main effects were qualified by a significant two-way interaction between them, $B=-.27, t(231)=3.31, p=.001$. Simple slope analysis indicated that, at lower levels of OCC (i.e., $1 S D$ below the mean), participants in the opportunity cost salient condition were less likely to buy the backpack than were participants in the control condition, $B=1.15, t(232)=2.48, p=.01$, but this condition difference was attenuated at higher levels of OCC (i.e., $1 S D$ above the mean), $B=.44, t(232)=1.75, p=.08$ (see Figure 2 for the simple slope lines). Thus the salience of opportunity cost information has a stronger effect on purchase decision among participants reported a weaker habit of considering opportunity cost but has a weaker effect among participants reported a stronger habit of considering opportunity cost. This pattern is in line with previous research that perceived resource constraint moderates the level of opportunity cost consideration among nonplanners but not among planners (Spiller, 2011). In other words, people with a stronger habit of considering opportunity cost in making purchase decisions seemed not very sensitive to the salience of opportunity cost information. However, for people who do not habitually consider opportunity cost, the salience of opportunity cost information played a stronger role in their purchase decisions: making the opportunity cost information salient significantly enhanced their likelihood of considering opportunity cost. No other effects were significant, $B s<.07$, $t s<.80, p s>.42$. 


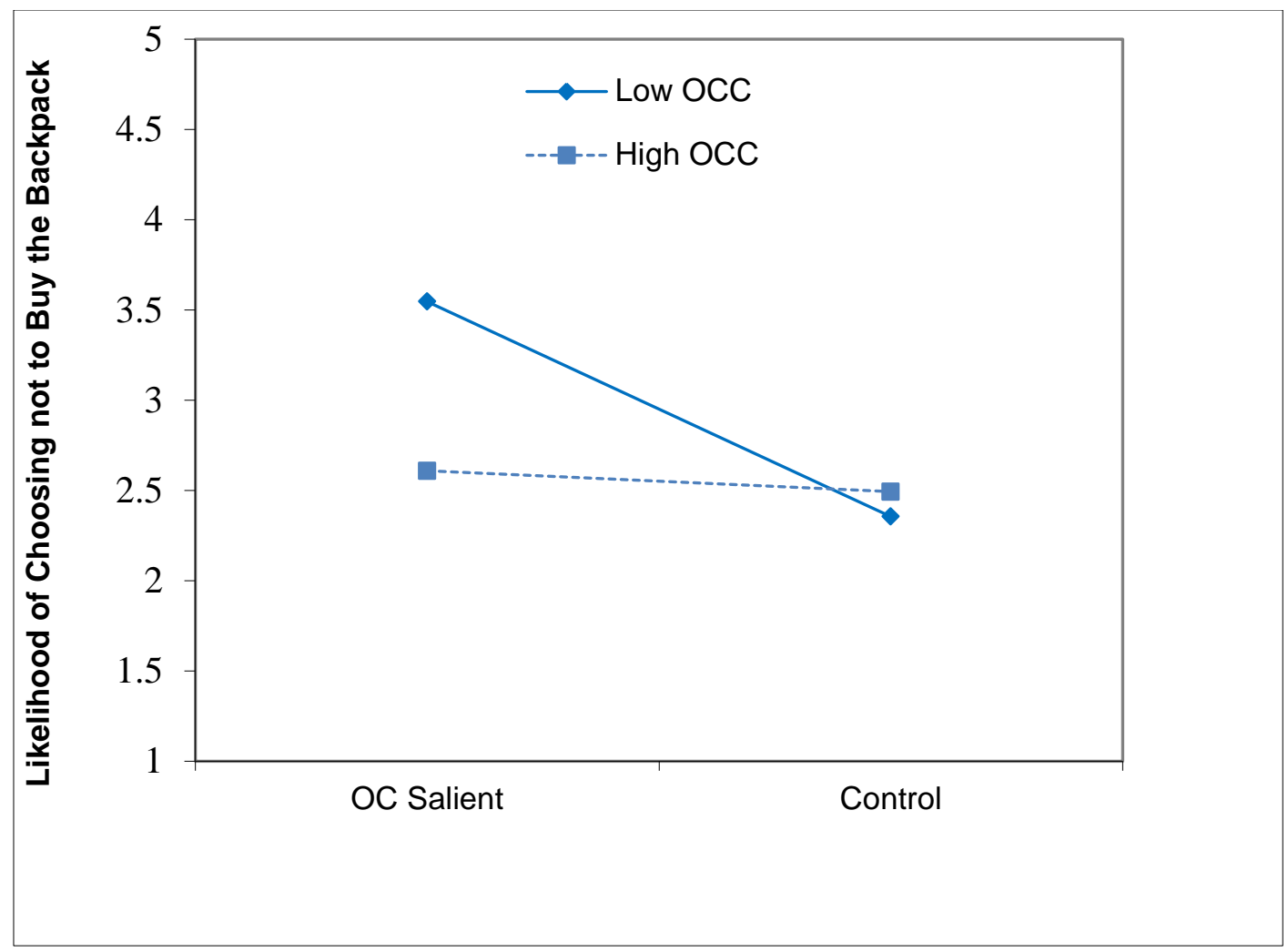

Figure 2. Relationship between choice and condition, depending on OCC, OCC $=$ opportunity cost consideration (Study 1).

Similarly, I explored if propensity to plan for money moderated the effect of culture and condition on choice. The overall model was significant, $F(7,231)=2.33, p=.03$. The results indicated that culture, $B=-.25, t(231)=2.0, p<.05$, condition, $B=-.37, t(231)=2.95, p=.004$, and PPM, $B=.21, t(231)=2.49, p=.01$ were significant predictors of choice. Chinese were less likely to buy the backpack than European Canadians. Participants were less likely to buy the backpack in the opportunity cost salient condition than in the control condition. In addition, the stronger participants' self-reported propensity to plan for money, the less likely they would choose to buy the backpack. None of the two-way and three-way interactions were significant, $B s<.13, t s<1.49, p s>.13$. 
Finally, I explored how spending habits as measured by the Spendthrift-Tightwad Scale (STS) moderated the effect of culture and condition on choice. The overall model was significant, $F(7,228)=5.08, p<.001$. The effect of culture only approached significance, $B=$ $.19, t(228)=1.70, p=.09$. Condition, $B=-.30, t(228)=2.72, p=.007$, and STS, $B=-.13, t(228)$ $=4.74, p<.001$, were significant predictors of choice. However, the main effects were qualified by a significant two-way interaction between condition and STS, $B=.06, t(228)=1.99, p<.05$, and a significant three-way interaction between condition, culture, and STS, $B=-.06, t(228)=$ $2.01, p<.05$. I followed up the three-way interaction by exploring the interaction between condition and STS among European Canadians and Chinese separately. Among European Canadians, the interaction between condition and STS was not significant, $B=.001, t(115)=.02$, $p=.98$. Among Chinese, the interaction between condition and STS was significant, $B=-.11$, $t(115)=2.59, p=.01$. Simple slope analysis for the interaction between condition and culture among Chinese indicated that, at lower levels of STS (i.e., $1 S D$ below the mean), Chinese were less likely to buy the backpack in the opportunity cost salient condition than in the control condition, $B=-.72, t(113)=2.81, p=.006$, but this condition difference was not found at higher levels of STS ( $1 S D$ above the mean), $B=.20, t(113)=.94, p=.35$ (see Figure 3 for simple slope lines). In summary, the salience of opportunity cost information led all groups but Chinese with higher levels of STS to make purchase decisions consistent with opportunity cost consideration. Thus, European Canadians and Chinese participants who had difficulty spending money were more susceptible to opportunity cost information, whereas Chinese who classified themselves as spendthrifts were immune to the salience of opportunity cost information. 


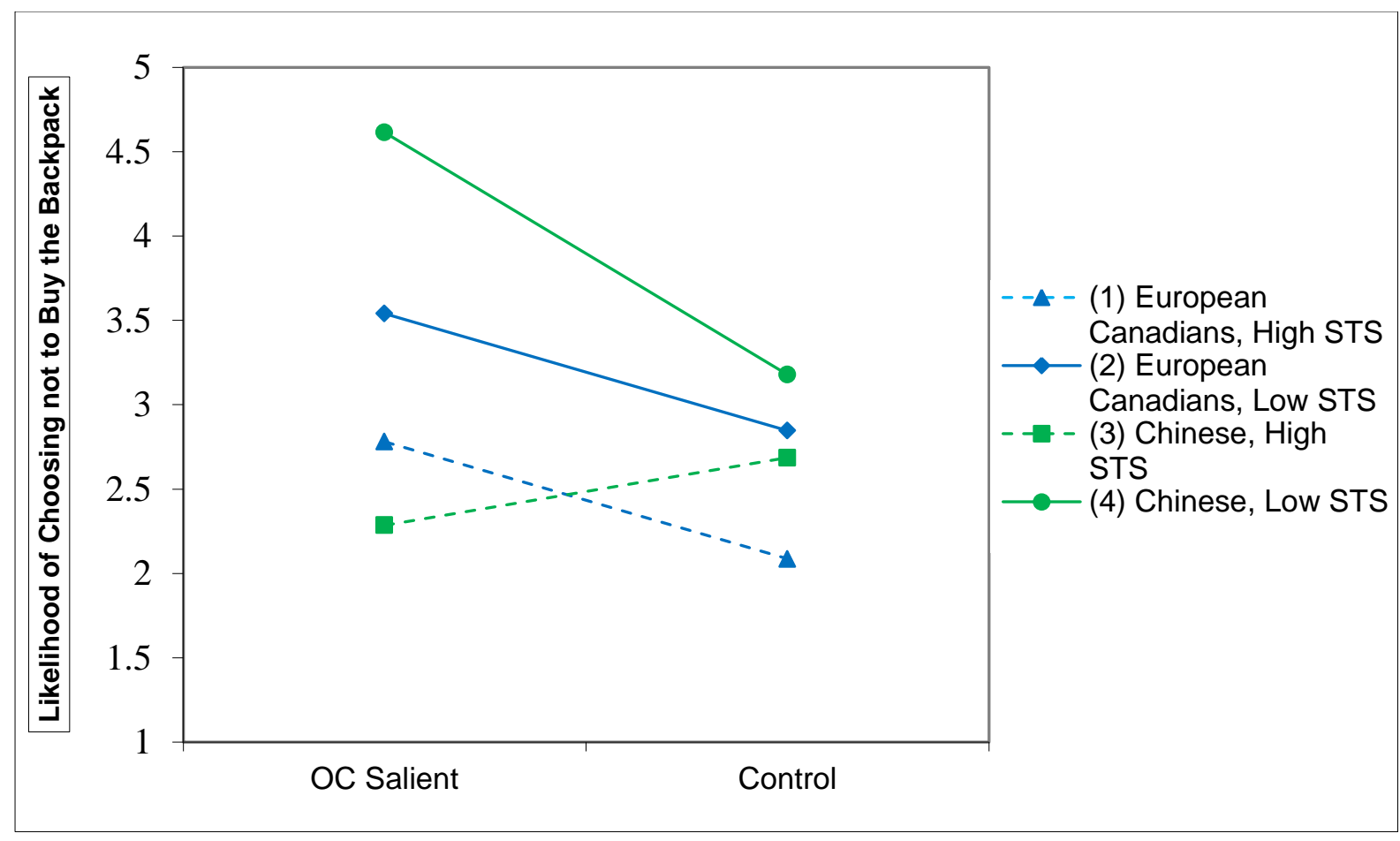

Figure 3. Relationship between choice and condition, depending on Culture and STS, STS = Spendthrift-Tightwad Scale (Study 1)

\section{Discussion}

In Study 1, participants generally considered opportunity cost to a greater extent in the opportunity cost salient condition than in the control condition indexed both by participants' likelihood of mentioning opportunity cost thoughts while making the purchase decision and by their choice. When individual differences in the habit of considering opportunity cost or in the propensity to plan for money were controlled for, Chinese were more likely to mention opportunity cost thoughts than were European Canadians while making the purchase decision. When individual differences in the habit of considering opportunity cost or in propensity to plan for money were controlled for, Chinese made choices more consistent with opportunity cost consideration than did European Canadians. In addition, the effect of opportunity cost salience on participants' purchase decision was significantly moderated by people's habits of considering 
opportunity cost and spending habits, respectively. Specifically, making opportunity cost information salient significantly increased people's likelihood of choosing not to buy the backpack (thus indicating a higher level opportunity cost consideration) among participants who reported a weaker habit of considering opportunity cost, but the effect was attenuated among participants reported a stronger habit of considering opportunity cost. The salience of opportunity cost information significantly increased the likelihood of choosing not to buy the backpack among all groups except for Chinese classified as spendthrifts. It is possible that Chinese spendthrifts did not care much about the opportunity cost in the current study as the product was relatively cheap. However, it is not clear why the same pattern was not observed among European Canadians.

There were some inconsistencies between the two-way ANOVA results and the moderated regression results. The main effect of culture was not significant in the two-way ANOVA but was significant in the moderated regression when OCC or PPM were included in the model and marginally significant when STS was included in the model. There are two possible explanations for this inconsistency: Firstly, including individual difference variables such as OCC or PPM in the model reduced the variance of error and in turn increased the power to detect the effect of culture on choice; Secondly, individual difference variables such as OCC or PPM might be suppressors of the effect of culture on choice such that when these individual difference variables were not included in the model (e.g., two-way ANOVA), the effect of culture on choice was suppressed. Correlation analyses verified that the individual difference variables were indeed suppressors for the effect of culture on choice. ${ }^{3}$

\footnotetext{
${ }^{3}$ The correlation between culture and OCC, culture and choice, OCC and choice were -.35 ( $p$ $=.01), .09(p=.17), .10(p=.12)$ respectively; the correlation between culture and PPM, culture
} 
Study 1 had several limitations. First, the price of the backpack (\$29.99/Y 110) seemed too low, which led to a high intention of choosing to buy the backpack and therefore little intention of choosing not to buy it (a floor effect). Indeed, a majority of the participants' (105 European Canadians and 101 Chinese) responses to the 8-point bipolar scale was below or equal to four (i.e., "slightly likely to buy the backpack"). This response is problematic because the strong preference for buying the backpack might suppress participants' likelihood of considering opportunity cost in making the decisions. Second, as the decision involved whether or not to buy the backpack (instead of choosing between two products), participants who did not need a backpack (or did not interested in having one) were more likely to choose not to buy it regardless of whether or not they considered opportunity cost. Lastly, even though I tried to make the money amount equivalent by using the Big Mac index to convert Canadians dollars to Chinese yuan, it was still possible that $\$ 29.99$ to Canadians was not equivalent to 110 yuan to Chinese, which would confound the cultural effects.

consideration and choice, PPM and choice were -.41 $(p=.01), .09(p=.17), .10(p=.12)$ respectively; the correlation between culture and STS, culture and choice, STS and choice were $.16(p=.05), .09(p=.17),-.27(p=.01)$ respectively. These inconsistent correlation signs signal suppression effects of each of the individual difference variables. Other approaches to identify suppressors (Pandey \& Elliott, 2010; Sharpe \& Roberts, 1997) also confirm these suppression effects. 


\section{Chapter 3: Study 2}

Study 2 was conducted to replicate Study 1 with a few improvements. First, I recruited all participants (including Chinese) at Queen's and presented the product price in Canadian dollars. This excluded the possibility that price difference and product information might confound participants' responses. Second, I introduced a more expensive product for university students - a laptop, which should help to prevent the floor effect observed in Study 1. Third, instead of deciding whether or not to buy a product as in Study 1, participants in Study 2 had to choose between two similar products. This should render participants' need for or interest in the product less relevant in their decisions. Study 2 also explored if the condition effect observed in Study 1 would be replicated using another manipulation of the salience of opportunity cost information—opportunity cost priming through a purchase listing task.

\section{Method}

\section{Participants}

Seventy-five European Canadian students (61 women, 14 men; $M_{\text {age }}=18.29$ years, $S D$ $=.71$ ), and 63 Chinese students ( 46 women, $17 \mathrm{men} ; M_{\text {age }}=20.03$ years, $S D=2.66$ ) at Queen's University participated in Study 2. ${ }^{4}$ Participants either received course credit or monetary compensation for their participation. All study materials were presented in English with product prices in Canadian dollars.

\section{Procedure}

Adapting a design from Frederick et al (2009), I randomly assigned participants to the opportunity cost priming condition or the control condition. All participants completed a

\footnotetext{
${ }^{4}$ Data of length of stay in Canada for Chinese participants were only available for 24 (38.1\%) Chinese participants in this study, which ranged from 1.17 to 20.92 years $(M=12.02, S D=5.81)$.
} 
decision-making task, in which they had to decide whether to buy a laptop with 500 GB hard drive or a similar laptop with 320 GB hard drive but $\$ 100$ cheaper. The only difference between the priming and control conditions was that participants in the priming condition completed a seemingly unrelated purchase listing task prior to the decision-making task, whereas participants in the control condition were not given this listing task. In the purchase listing task, participants listed things (either one item or multiple items) that they could buy using $\$ 100$ on a blank page of paper. The purchase listing task was supposed to prime participants with the opportunity costs of spending an additional $\$ 100$ for the more expensive laptop.

Participants indicated their choice on an 8-point scale $(1=$ definitely choose option $\mathrm{A}-$ the more expensive one, $8=$ definitely choose option B - the cheaper one). Then, they listed any thoughts they had while deciding which option to choose and indicated to what extent making the choice would influence their ability to buy other things (see Appendix D for details). Afterwards, participants completed the 3-item Opportunity Cost Consideration Scale (Spiller, 2011). ${ }^{5}$ Finally, participants answered demographic questions such as age, gender, ethnicity, family income, average amount of pocket money for each month, and perceived financial security (see Appendix E for details).

\section{Results}

\section{Presence of Opportunity Cost Thoughts}

Two research assistants blind to the research hypothesis coded participants thoughts using the same scheme as in Study 1. The inter-coder agreement was $86 \%$; disagreements were

\footnotetext{
${ }^{5}$ The Standardized Cronbach's alpha of the Opportunity Cost Consideration Scale was .86 for European Canadians and .81 for Chinese in this study. Exploratory factor analysis using Principal Axis Factoring extraction with Direct Oblimin rotation indicated that all items loaded highly onto a single OCC factor for both samples.
} 
resolved through discussion. A binary logistic regression was conducted to examine how participants' consideration of opportunity $\operatorname{cost}(0=$ not considering opportunity cost, $1=$ considering opportunity cost) could be predicted by culture (European Canadians vs. Chinese), condition (Opportunity cost priming vs. Control), centered OCC, and all the two-way and threeway interactions. The overall model with the simultaneous entering method was not significant, $\chi^{2}(7)=11.13, p=.13$, Nagelkerke $\mathrm{R}^{2}=.12$. Only culture was a marginally significant predictor of the presence of opportunity cost thoughts, $W^{2}(1)=3.66, p=.06$. Chinese were 2.50 times more likely to mention opportunity cost thoughts than were European Canadians. No other effects approached significance, $\exp (B)_{s}<1.73, W^{2}(1) \mathrm{s}<2.10$, ps $>.14$.

\section{Likelihood of Choosing the Cheaper Laptop}

I conducted a two-way ANOVA with culture (European Canadians vs. Chinese) and condition (Opportunity cost priming vs. Control) as independent variables and the likelihood of choosing option B (the cheaper laptop) as the dependent variable. As predicted, there was a significant main effect of culture, $F(1,134)=6.15, p=.01, \eta_{\mathrm{p}}^{2}=.04$. Chinese $(M=5.37, S D=$ 2.20) were significantly more likely to choose the cheaper laptop than were European Canadians $(M=4.41, S D=2.31)$. In other words, Chinese participants considered opportunity cost more than did European Canadians. However, the main effect of condition and the interaction between culture and condition were not significant, $F(1,134)=.07, p=.79$ and $F(1,134)=2.35$, $p=.13$, respectively. I conducted simple effects analysis to directly examine my hypotheses. The cultural main effect was especially strong for participants in the control condition. As seen in Figure 4, European Canadians were less likely than were Chinese to choose the cheaper laptop in the control condition when not being primed with opportunity cost, $F(1,134)=7.92, p$ $=.006$. However, in the opportunity cost priming condition, European Canadians and Chinese 
did not differ in their likelihood of choosing the cheaper option, $F(1,134)=0.46, p=.50$.

Although the mean was in the expected direction, European Canadian participants' choice did not differ between the opportunity cost priming condition and the control condition, $F(1,134)$ $=.87, p=.35$. The trend for Chinese participants was reversed compared to that of European Canadians, though, their likelihood of choosing the cheaper laptop did not differ between the opportunity cost priming condition and control condition either, $F(1,134)=1.50, p=.22$.

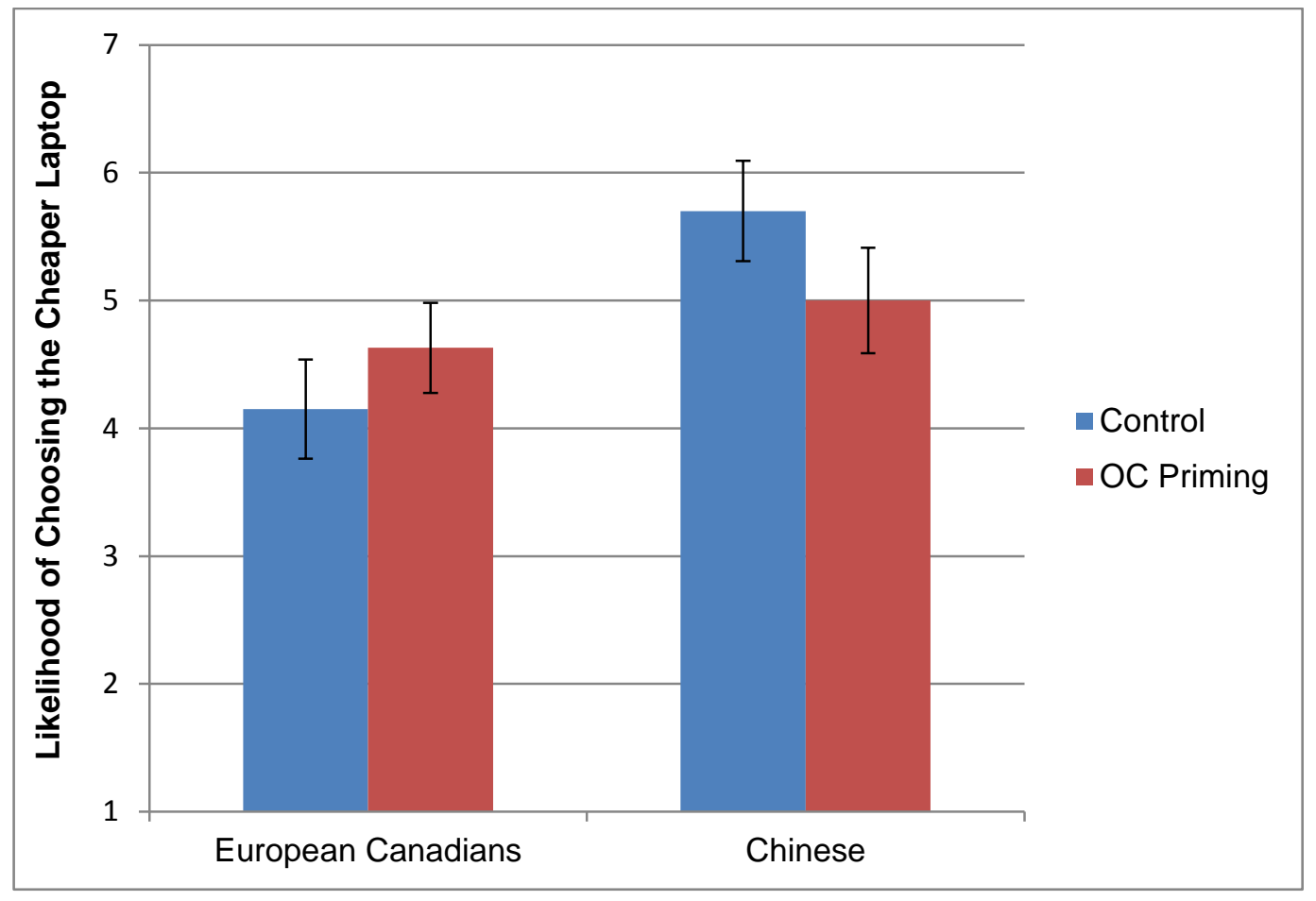

Figure 4. Differences in the Likelihood of Choosing the Cheaper Laptop as a Function of Culture and OC Salience

Overall, participants' likelihood of choosing the cheaper laptop was negatively correlated with family income, $r=-.32, p=.001$, indicating that the higher of the participants' family income, the less likely it was for them to choose the cheaper laptop. European Canadians $(M=$ $4.89, S D=1.37)$ reported a higher level of family income than did Chinese $(M=3.43, S D=$ $1.71), t(133)=5.51, p<.001$. However, European Canadians and Chinese did not differ in their 
financial security, perceived affordability to buy other things, and the amount of pocket money they had each month, $t s<1.37, p s>.17$. Therefore, we included family income as a covariate in the 2 (culture) $x 2$ (condition) ANOVA. The results showed that family income had a significant effect on choice, $F(1,129)=8.96, p=.003$, but the culture main effect was no longer significant, $F(1,129)=.45, p=.60$. The condition effect and the interaction between culture and condition remained nonsignificant, $F_{s}(1,129)<1.77, p s>.18$.

I conducted a series of regression analyses to determine if family income confounded the relationship between culture and the likelihood of choosing the cheaper laptop (MacKinnon, Krull, \& Lockwood, 2000). In the first step, culture was a significant predictor of the likelihood of choosing the cheaper laptop, $B=.92, t(136)=2.32, p=.02$. In the second step, culture was a significant predictor of family income, $B=-1.46, t(132)=5.51, p<.001$. Finally, family income and culture were entered together to predict the likelihood of choosing the cheaper laptop; only family income was a significant predictor of the likelihood of choosing the cheaper laptop, $B=-$ $.39, t(131)=3.15, p=.002$, rendering the effect of culture on the likelihood of choosing the cheaper laptop no longer significant, $B=.34, t(131)=.80, p=.42$. The Sobel test for significance in the reduction of the direct path was significant $(z=2.70, p=.007)$. The Preacher and Hayes (2004) bootstrapped result with 2000 resamples produced a value representing the mediation effect (.58) and a 99\% CI of the value was [.097, 1.22]. This confidence interval did not include 0 , indicating that family income confounded the relationship between culture and the likelihood of choosing the cheaper laptop.

I conducted a moderated regression analysis to explore if the habit of considering opportunity cost in making purchase decisions moderated the effects of condition and culture on choice as that in Study 1. To reduce multicollinnearity, I centered OCC average and did effect 
coding for the two categorical variables — culture $(1=$ European Canadians, $-1=$ Chinese $)$ and condition $(1$ = control, $-1=$ opportunity cost priming). The overall model only approached significance, $F(7,130)=1.93, p=.07$. Only culture was a significant predictor of choice, $B=-$ $.45, t(130)=2.29, p=.02$, such that Chinese were more likely to buy the cheaper laptop than were European Canadians. No other effect was significant, $B s<.25$, $t s<1.46$, $p s>.14$. These results indicated that OCC did not play a moderating role of the main effects in the current study.

\section{Discussion}

In Study 2, I found a higher degree of opportunity cost consideration among Chinese than among European Canadians, but this effect was no longer significant when family income was included in the analysis. Confound analysis demonstrated that family income confounded the effect of culture on choice. Overall, Chinese participants reported a lower level of family income than did European Caucasian participants, and lower family income led to more choice consistent with opportunity cost consideration. This indicated that it was family income rather than culture that drove the differences in choice between European Canadians and Chinese. However, results based on another index of opportunity cost consideration-presence of opportunity cost thoughts - through the thought listing task revealed that Chinese were marginally more likely to consider opportunity cost than European Canadians even when they made similar decisions. ${ }^{6}$ This implies that, at least to some extent, Chinese are indeed more likely to consider opportunity cost than European Canadians.

\footnotetext{
${ }^{6}$ Among those participants who chose the cheaper option, Chinese participants $(40.9 \%)$ displayed a marginally higher likelihood of mentioning opportunity cost thoughts than European Canadians $(21.6 \%), \chi^{2}(1, N=81)=3.43, p=.06$.
} 
Priming did not have any significant effect on participants' purchase decision. Thus, the opportunity cost priming effect reported by Frederick et al. (2009) was not replicated in the current study. The only differences between Study 2 and Frederick et al. (2009) were that the price difference between the two products changed from $\$ 20$ to $\$ 100$ and that the product changed from a cellphone to a laptop. It is probably that other factors unexplored in the current study may moderate the effect of opportunity cost priming on people's purchase decision. 


\section{Chapter 4: General Discussion}

Across two studies, I explored cultural differences in opportunity cost consideration. My first hypothesis was that European Canadians would be less likely to consider opportunity cost than Chinese, especially when opportunity cost information was not made salient. This hypothesis was generally supported in both studies. Study 1 showed that Chinese were more likely to think about opportunity cost while making the decision than European Canadians. Chinese also made choice decisions more consistent with opportunity cost consideration than Canadians did, when controlling for individual differences in habits of considering opportunity cost consideration or propensity to plan for money. In Study 2, Chinese displayed a higher degree of opportunity cost consideration overall, in both the likelihood of mentioning opportunity cost thoughts and choice, than did European Canadians.

The second hypothesis that European Canadians would benefit more from the salience of opportunity cost information than Chinese was not supported. In Study 1, participants in the opportunity cost salient condition considered opportunity cost to a greater extent than did participants in the control condition. Although this pattern looked particularly true for European Canadian participants, the culture and condition interaction did not approach significance. Salience of opportunity cost information did not produce any significant effect in Study 2.

The cultural difference in opportunity cost consideration observed in Study 2 became non-significant when family income was included as a covariate in the analysis, indicating that family income accounted for cultural differences in opportunity cost consideration in the current study. Although mediation analysis indicated that family income confounded the effect of culture on choice, it is not clear how family income account for cultural difference in opportunity cost consideration. One possibility is that cultural differences in family income may lead to 
different level of perceived resource constraint. However, we did not found any cultural differences on perceived affordability to buy other things, financial security, and average amount of pocket money in Study 2. Mediation analyses indicated that perceived affordability to buy other things, financial security, and average amount of pocket money did not mediate the relationship between family income and choice. ${ }^{7}$ Another possibility is that family income may have afforded people with different family environment and life experience, which could foster different attitudes towards spending money and purchasing behavior. As indicated in Study 1, however, propensity to plan for spending money was indeed higher among European Canadians than among Chinese. Furthermore, greater planning propensity among Canadians did not transform into greater opportunity cost consideration, in either thoughts or decisions. Thus, future research is needed to explore the mechanism for family income to affect opportunity cost consideration.

The current research contributes to research on culture and decision-making. Previous research on opportunity cost consideration was predominantly conducted in North America (Becker et al., 1974; Frederick et al., 2009; Northcraft \& Neale, 1986; Spiller, 2011). Little attention had been paid to cross-cultural variance in opportunity cost consideration. As far as I know, the current research was among the first to explore cultural differences in opportunity cost consideration. Although inconclusive, the results imply that opportunity cost consideration varies, at least to some extent, across cultures. In line with Weber et al.'s (2000, 2010) advocacy for more research on the intersection between culture and decision-making, future research

\footnotetext{
${ }^{7}$ The Sobel test for the significance of reduction of the direct path from family income to choice were not significant for pocket money $(Z=-.03, p=.98,95 \%$ confidence interval $[-.0369, .022])$, affordability $(Z=-.70, p=.48,95 \%$ confidence interval $[-.0695, .0096])$, and financial security $(Z=1.12, p=.26,95 \%$ confidence interval $[-.0341, .1761])$, respectively.
} 
should explore how culture interacts with other factors (e.g., the salience of opportunity cost information, propensity to plan, size of purchase) in influencing people's judgment and decisions.

The present study also highlights the importance of using multiple indices in crosscultural research as not all the indices are cross-culturally reliable. In the current research, results based on participants' responses to the opportunity cost consideration scale were inconsistent across two studies. It was not in line with the other two indices (i.e., choice rating and presence of opportunity cost thoughts) of opportunity cost consideration either. For example, Chinese participants' intention to choose the cheaper laptop was negatively correlated with their self-reported level of opportunity cost consideration in Study $2(r=-.28, p=.05)$, which was puzzling. Perhaps the self-report scale measures something quite different from what the context specific purchase scenario reveals. Future research is needed to develop and verify the reliability and validity of these measures in general and for cross-cultural research on opportunity cost consideration in particular.

\section{Limitations}

Several limitations of the current research make the results inconclusive. One limitation is that although I tried to make the price comparable for European Caucasian and Chinese participants using the Big Max Index transformation in Study 1, the price might still have been perceived differently (e.g., expensive or cheap) across cultures, which could, in turn, confound the results. However, this limitation was not a problem in Study 2 because all product prices were presented in Canadian dollars. Future research could measure and include participants' perception of the product price as a covariate.

Another limitation is that other factors that were not measured in the current research might have attenuated the effect of priming opportunity cost in decision-making. Although the 
method worked in the original study by Frederick et al (2009) among American students, the effect was not observed in Study 2. One possibility is that Frederick et al. (2009) used a larger sample than I did (i.e., 80 participants in each cell of their study vs. 32 participants per cell in Study 2). ${ }^{8}$ Another possibility is that buying a laptop is a relatively big purchase for university students, and the size of the purchase could moderate the likelihood of considering opportunity cost in decision-making. Future research could explore the moderating effect of these factors and work on developing new methods of manipulating the salience of opportunity cost information.

Third, choosing whether or not to buy a product (or the likelihood of choosing to buy a product) might not be a good index of opportunity cost consideration because it is influenced by multiple factors such as price, need, and preference. This problem is especially true in the crosscultural context, as previous research has demonstrated substantial cross-cultural differences in the determinants of consumer behavior (Luna \& Gupta, 2001; de Mooij \& Hofstede, 2011). In the current studies, in addition to asking participants to rate their choice for each option, I tried to elicit their thoughts in making the decisions, which enriched the understanding of opportunity cost consideration in purchase decision-making. For instance, the presence of opportunity cost thoughts in Study 2 indicated that Chinese were slightly more likely to think about opportunity costs than were European Canadians despite the fact that they made similar decisions (e.g., choosing the cheaper laptop). In other words, in previous research (Frederick et al., 2009) and the current study, the choice intention measure may not be an ideal proxy capturing opportunity cost consideration in everyday purchase decision-making. Therefore, to better capture the

\footnotetext{
${ }^{8}$ I ran study 2 at the end of the term and recruited as many participants as I could. But unfortunately, I could not get a bigger sample (especially for Chinese).
} 
phenomenon of opportunity cost consideration, new indices of opportunity cost consideration need to be developed and verified.

\section{Future Directions}

The results of the current study revealed that family income difference confounded the relationship between culture and opportunity cost consideration (Study 2). However, it is not clear how family income transformed to opportunity cost consideration in the current study and if there are psychological variables (other than the socioeconomic variables) that lead to cultural differences in opportunity cost consideration. Thus, future research is warranted to tease apart the effect of culture and family income on opportunity cost consideration. For instance, future research could compare European Canadians and Chinese with similar family incomes (e.g., Chinese from Hong Kong or Singapore) to explore if the culture main effect observed in the current study could be replicated. If there are indeed cultural differences in opportunity cost consideration after matching socioeconomic variables (e.g., family income), a fruitful further step would be to investigate the underlying mechanisms of this phenomenon. For instance, future research could explore if focalism (Lam, Buehler, McFarland, Ross, \& Cheung, 2005) accounts for cultural differences in opportunity cost consideration.

Whereas the current research focuses on cultural differences in considering opportunity cost while making purchase decisions, future research can expand it into decision-making with other resources such as time, relationships, and environment sustainability. For instance, the well documented phenomenon of the planning fallacy (Buehler, Griffin, \& Ross, 1994; Buehler, Griffin, \& Peetz, 2010) may be caused by the fact that people do not consider the opportunity cost of future time commitments sufficiently. As people tend to perceive that they have more time in the future (Zauberman \& Lynch, 2005), they are more likely to underestimate other tasks 
that may compete for their limited time resources when they make plans for the future. Exploring cultural differences in opportunity cost consideration in these nonfinancial domains also has the advantage of circumventing the interfering effect of culturally contingent socioeconomic indices (e.g., family income) encountered in the current research.

Future research also could explore the implication of opportunity cost consideration in consumer behavior management. For example, strategies that prompt opportunity cost consideration could reduce impulsive consumption (Baumeister, 2002). Specifically, given that participants generally benefit from the salience of opportunity cost information (Frederick, 2009), increasing the salience of opportunity cost through asking questions like "What other items could I buy with the money I am going to spend?” might enhance consideration of opportunity cost and, in turn, decrease impulsive consumption.

\section{Conclusion}

Two studies were conducted to explore cultural differences in opportunity cost consideration. I found that Chinese displayed a higher level of opportunity cost consideration than European Canadians (presence of opportunity cost thoughts and choice when controlling for individual difference measures in Study 1; Study 2). However, family income confounded with culture in accounting for the effect (Study 2). I also found in Study 1 but not Study 2 that making opportunity cost information salient significantly increased people's consideration of opportunity cost. Taken together, the results in the current study were somewhat mixed and inconclusive. Future research is warranted to fully explore how and when culture differs in opportunity cost consideration. Future research with refined measures of opportunity cost consideration will enrich our understanding of the factors that enhance or constrain opportunity cost consideration. By documenting the phenomenon of opportunity cost neglect or consideration and its underlying mechanism, this line of research has implications for informing 
people on how to make optimal decisions in their everyday life. For example, enhancing opportunity cost consideration could help people to resist many decision pitfalls such as impulsive consumption and planning fallacy in the short term, and in turn, to improve the efficiency of both personal (e.g., money, time) and collective resources management in the long run. 


\section{References}

Ariely, D. (2008). Predictably irrational: The hidden forces that shape our decisions. New York, NY: Harper Collins Publishers.

Baumeister, R. F. (2002). Yielding to temptation: Self-control failure, impulsive purchasing, and consumer behavior. Journal of Consumer Research, 28(4), 670-676.

Becker, S. W., Ronen, J., \& Sorter, G. H. (1974). Opportunity costs - an experimental approach. Journal of Accounting Research, 12(2), 317-329.

Big Mac Index, http://www.economist.com/blogs/graphicdetail/2012/01/daily-chart-3 Retrieved on September 1st, 2012.

Buehler, R., Griffin, D., \& Peetz, J. (2010). The planning fallacy: Cognitive, motivational, and social origins. Advances in Experimental Social Psychology, 43, 1-62.

Buehler, R., Griffin, D., \& Ross, M. (1994). Exploring the "planning fallacy": Why people underestimate their task completion times. Journal of Personality and Social Psychology, 67(3), 366-381.

Luna, D., \& Gupta S.F. (2001). An integrative framework for cross-cultural consumer behavior. International Marketing Review, 18(1), 45-69.

de Mooij, M., \& Hofstede, G. (2011). Cross-cultural consumer behavior: A review of research findings. Journal of International Consumer Marketing, 23(3-4), 181-192. 
Frederick, S., Novemsky, N., Wang, J., Dhar, R., \& Nowlis, S. (2009). Opportunity cost neglect. Journal of Consumer Research, 36(4), 553-561. doi: 10.1086/599764

Friedman, L. A., \& Neumann, B. R. (1980). The effects of opportunity costs on project investment decisions: A replication and extension. Journal of Accounting Research, 18(2), 407-419.

Heine, S. J. (2010). Cultural Psychology. In Fiske S. T., Gilbert D. T. and Lindzey G. (Eds.), Handbook of Social Psychology (5 ${ }^{\text {th }}$ edition), (pp1423-1464). Hoboken, NJ: John Wiley \& Sons Inc.

Ji, L., Peng, K., \& Nisbett, R. E. (2000). Culture, control, and perception of relationships in the environment. Journal of Personality and Social Psychology, 78(5), 943-955. doi: $10.1037 / 0022-3514.78 .5 .943$

Jones, S. K., Frisch, D., Yurak, T. J., \& Kim, E. (1998). Choices and opportunities: Another effect of framing on decisions. Journal of Behavioral Decision Making, 11(3), 211-226. doi: 10.1002/(SICI)1099-0771(199809)11:3<211::AID-BDM298>3.0.CO;2-O

Lam, K. C. H., Buehler, R., McFarland, C., Ross, M., \& Cheung, I. (2005). Cultural differences in affective forecasting: The role of focalism. Personality and Social Psychology Bulletin, 31(9), 1296-1309. doi: 10.1177/0146167205274691

Legrenzi, P., Girotto, V., \& JohnsonLaird, P. N. (1993). Focussing in reasoning and decision making. Cognition, 49(1-2), 37-66. 
Lynch, J. G. J., Netemeyer, R. G., Spiller, S. A., \& Zammit, A. (2010). A generalizable scale of propensity to plan: The long and the short of planning for time and for money. Journal of Consumer Research, 37(1), 108-128.

MacKinnon, D. P., Krull, J. L., \& Lockwood, C. M. (2000). Equivalence of the mediation, confounding and suppression effect. Prevention Science, 1(4), 173-181.

Masuda, T., Gonzalez, R., Kwan, L., \& Nisbett, R. E. (2008). Culture and aesthetic preference: Comparing the attention to context of East Asians and Americans. Personality and Social Psychology Bulletin, 34(9), 1260-1275. doi: 10.1177/0146167208320555

Masuda, T., \& Nisbett, R. E. (2001). Attending holistically versus analytically: Comparing the context sensitivity of Japanese and Americans. Journal of Personality and Social Psychology, 81(5), 922-934. doi: 10.1037/0022-3514.81.5.922

Neumann, B. R., \& Friedman, L. A. (1978). Opportunity costs: Further evidence through an experimental replication. Journal of Accounting Research, 16(2), 400-410.

Nisbett, R. E. (2003). The geography of thought: How Asians and Westerners think differently ... and why. New York, NY: Free Press.

Nisbett, R. E., \& Norenzayan, A. (2002). Culture and cognition. In Pashler H., Medin D. (Eds.), Steven's Handbook of Experimental Psychology ( $3^{\text {rd }}$ edition), (pp.561-597). Hoboken, NJ: John Wiley \& Sons Inc. 
Nisbett, R. E., Peng, K., Choi, I., \& Norenzayan, A. (2001). Culture and systems of thought: Holistic versus analytic cognition. Psychological Review, 108(2), 291-310. doi: 10.1037/0033-295X.108.2.291

Northcraft, G. B., \& Neale, M. A. (1986). Opportunity costs and the framing of resource allocation decisions. Organizational Behavior and Human Decision Processes, 37(3), 348356. doi: 10.1016/0749-5978(86)90034-8

Pandey, S., \& Elliott, W. (2010). Suppressor variables in social work research: Ways to identify in multiple regression models. Journal of the Society for Social Work and Research, 1(1), $28-40$.

Posavac, S. S., Kardes, F. R., Sanbonmatsu, D. M., \& Fitzsimons, G. J. (2005). Blissful insularity: When brands are judged in isolation from competitors. Marketing Letters, 16(2), 87-97.

Posavac, S. S., Sanbonmatsu, D. M., Kardes, F. R., \& Fitzsimons, G. J. (2004). The brand positivity effect: When evaluation confers preference. Journal of Consumer Research, 31(3), 643-651.

Preacher, K. J., \& Hayes, A. F. (2004). SPSS and SAS procedures for estimating indirect effects in simple mediation models. Behavior Research Methods, Instruments \& Computers Special Issue: Web-based archive of norms, stimuli, and data: Part 2, 36, 717-731.

Rick, S. I., Cryder, C. E., \& Loewenstein, G. (2008). Tightwads and spendthrifts. Journal of Consumer Research, 34(6), 767-782. 
Sharpe, N. R., \& Roberts, R. A. (1997). The relationship among sums of squares, correlation coefficients, and suppression. The American Statistician, 51(1), 46-48.

Shavit, T., Rosenboim, M., \& Malul, M. (2011). Opportunity costs in buying and short selling do they really matter? Economics Letters, 112(1), 122-124.

Spiller, S. A. (2011). Opportunity cost consideration. Journal of Consumer Research, 38(4), 595610. doi: $10.1086 / 660045$

Thaler, R. (1980). Toward a positive theory of consumer choice. Journal of Economic Behavior \& Organization, 1(1), 39-60. doi: 10.1016/0167-2681(80)90051-7

Vera-Muñoz, S. C. (1998). The effects of accounting knowledge and context on the omission of opportunity costs in resource allocation decisions. The Accounting Review, 73(1), 47-72.

Weber, E. U., \& Hsee, C. K. (2000). Culture and individual judgment and decision making. Applied Psychology: An International Review, 49(1), 32-61.

Weber, E. U., \& Morris, M. W. (2010). Culture and judgment and decision making: The constructivist turn. Perspectives on Psychological Science, 5(4), 410-419.

Zauberman, G., \& Lynch, J. G. J. (2005). Resource slack and propensity to discount delayed investments of time versus money. Journal of Experimental Psychology: General, 134(1), $23-37$. 


\section{Appendix A}

\section{Purchasing Scenario in Study 1}

Instructions: we are interested in people's purchase decisions in everyday life; please indicate your preferences based on the following scenario (the italic content is the scenario presented to participants in the opportunity cost salient condition).

Imagine that you have been saving some extra money to make some purchases, and on your most recent visit to a supermarket you come across a special sale on a new traveling backpack. It is your favorite style (e.g. brand, material, capacity etc.). This particular traveling backpack is one you have been thinking about buying for a long time. It is available at a special sale price of $\$ 29.99$.

Please consider the following two options:

(A) Buy this backpack

(B) Not buy this backpack [Keep the \$29.99/ ¥110 for other purchases]

the following scale:

12

$2 \quad 3$

4

5

6

7

8

Definitely Very Somewhat Slightly Slightly Somewhat Very Definitely

Choose likely to likely to likely to likely to likely to likely to Choose

Option A choose A choose A choose A choose B choose B choose B Option B

Please list any thoughts you had while deciding which option to choose:

1.

2.

3. 
4.

5.

6.

7.

8.

How much extra money did you imagine you had saved while considering the above choice?

$\$$

Why did you choose the option as you did in the situation on the previous page?

While making the above choice, to what extent do you think that the choice will affect your affordability to buy other things?

1

2

3

not at all
4

5

6 7

-

a great deal 


\section{Appendix B \\ Scales Used in Study 1 \\ Opportunity Cost Consideration Scale}

1. I often think about the fact that spending money on one purchase now means not spending money on some other purchases later.

Strongly disagree

Strongly agree

$\begin{array}{lllllll}1 & 2 & 3 & 4 & 5 & 6 & 7\end{array}$

2. When I am faced with an opportunity to make a purchase, I try to imagine things in other categories I might spend that money on.

Strongly disagree Strongly agree

$\begin{array}{lllllll}1 & 2 & 3 & 4 & 5 & 6 & 7\end{array}$

3. I often consider other specific items that I would not be able to buy if I made a particular purchase.

Strongly disagree

Strongly agree

$\begin{array}{lllllll}1 & 2 & 3 & 4 & 5 & 6 & 7\end{array}$




\section{Propensity to Plan for Money Scale - Long Term}

1. I set financial goals for the next 1-2 months for what I want to achieve with my money.

Strongly disagree ..Strongly agree

$\begin{array}{lllllll}1 & 2 & 3 & 4 & 5 & 6 & 7\end{array}$

2. I decide beforehand how my money will be used in the next 1-2 months.

Strongly disagree ..Strongly agree

$\begin{array}{lllllll}1 & 2 & 3 & 4 & 5 & 6 & 7\end{array}$

3. I actively consider the steps I need to take to stick to my budget in the next 1-2 months.

Strongly disagree ...Strongly agree

$\begin{array}{lllllll}1 & 2 & 3 & 4 & 5 & 6 & 7\end{array}$

4. I consult my budget to see how much money I have left for the next 1-2 months. Strongly disagree Strongly agree

$\begin{array}{lllllll}1 & 2 & 3 & 4 & 5 & 6 & 7\end{array}$

5. I like to look for my budget for the next 1-2 months in order to get a better view of my spending in the future.

Strongly disagree Strongly agree

$\begin{array}{llllllll}1 & 2 & 3 & 4 & 5 & 6 & 7\end{array}$

6. It makes me feel better to have my finances planned out in the next 1-2 months. Strongly disagree Strongly agree

$\begin{array}{llllllll}1 & 2 & 3 & 4 & 5 & 6 & 7\end{array}$




\section{Spendthrift-Tightwad Scale}

1. Which of the following descriptions fits you better?

$\begin{array}{lllllllllll}1 & 2 & 3 & 4 & 5 & 6 & 7 & 8 & 9 & 10 & 11\end{array}$

Tightwad

About the

Spendthrift

(difficulty

same or

(difficulty

spending

neither

controlling

money)

spending)

2. Some people have trouble limiting their spending: they often spend money-for example on clothes, meals, vacations, phone calls - when they would do better not to. Other people have trouble spending money. Perhaps because spending money makes them anxious, they often don't spend money on things they should spend it on.

a. How well does the first description fit you? That is, do you have trouble limiting your spending?

$\begin{array}{ccccc}1 & 2 & 3 & 4 & 5 \\ \text { Never } & \text { Rarely } & \text { Sometimes } & \text { Often } & \text { Always }\end{array}$

b. How well does the second description fit you? That is, do you have trouble spending money?

1

Never
2

Rarely
3

Sometimes
4

Often
5

Always 
3. Following is a scenario describing the behavior of two shoppers. After reading about each shopper, please answer the question that follows.

Mr. A is accompanying a good friend who is on a shopping spree at a local mall. When they enter a large department store, Mr. A sees that the store has a "one-day-only-sale" where everything is priced 10-60\% off. He realizes he doesn't need anything, yet can't resist and ends up spending almost $\$ 100$ on stuff.

Mr. B is accompanying a good friend who is on a shopping spree at a local mall. When they enter a large department store, Mr. B sees that the store has a "one-day-only-sale" where everything is priced $10-60 \%$ off. He figures he can get great deals on many items that he needs, yet the thought of spending the money keeps him from buying the stuff. In terms of your own behavior, who are you more similar to, Mr. A or Mr. B?

or neither 


\section{Appendix C}

\section{Demographics for Study 1}

1. Your age:

2. Your gender (check one): Male Female

3. Your ethnicity:

4. Average pocket money you have each month (exclude basic living expenses): $\$$

5. Please indicate which of the following category best describes your family income:
2
3
4
5
6

1

less than $\$ 25,000$ to $\$ 50,000$ to $\quad \$ 75,000$ to $\$ 100,000$ to $\$ 125,000+$

$\$ 25,000 \quad \$ 49,999 \quad \$ 74,999 \quad \$ 100,000 \quad \$ 124,999$

6. Please indicate your mother's education level:
1
2
3
4
6
7

no formal less than primary secondary college or postgraduate don't know

education primary education education university

education

7. Please check a circle to indicate your father's education level:
1
2
3
4
5
6
7

no formal less than primary secondary college or postgraduate don't know

education primary education education university

education

8. Please indicate to what extent do you feel financially secure?
1
2
3
4
5
6
7

not at all

a great deal 


\title{
Appendix D
}

\section{Purchasing Scenario in Study 2}

\author{
Purchase Listing Task
}

Vivid Writing about Everyday Purchase

We are interested in knowing about university students' purchasing behavior. In the following space please list things (either one item or multiple items, please be specific) that you could buy using \$100:

\section{Decision-making Task}

We are collaborating with the Marketing Department from Queen's School of Business. They would like to know university student's purchase intentions for two laptops. Please read the following scenario and indicate your purchase preference.

Imagine that you have been saving some extra money to make some purchases, and on your recent visit to a digital technology store you come across two laptops of the same brand that are on sale. The laptops have the features you prefer, and you have been thinking about buying a laptop for a long time.

You have two options:

(A) Buy the 14" Laptop with Intel i3 $2.4 \mathrm{GHz}$ processor and 500 GB Hard Drive, which costs $\$ 579.95$

(B) Buy the 14" Laptop with Intel i3 $2.4 \mathrm{GHz}$ processor and $320 \mathrm{~GB}$ Hard Drive, which costs $\$ 479.95$

1. Please check the circle that best indicates your likelihood of choosing option A or B:

\begin{tabular}{|c|c|c|c|c|c|c|c|}
\hline Definitely & Very & Somewhat & Slightly & Slightly & Somewhat & Very & Definitely \\
\hline Choose & likely to & likely to & likely to & likely to & likely to & likely to & Choose \\
\hline Option A & choose A & choose A & choose A & choose $\mathbf{B}$ & choose $\mathbf{B}$ & choose $\mathbf{B}$ & Option $\mathbf{I}$ \\
\hline
\end{tabular}


2. Please list any thoughts (or reason) you had while deciding which option to choose in the above situation:

3. While making the choice on the previous page, to what extent do you think that your choice will affect your affordability to buy other things?

$\begin{array}{lllllll}1 & 2 & 3 & 4 & 5 & 6 & 7\end{array}$

not at all

a great deal

4. Please indicate to what extent do you feel financially secure?

$\begin{array}{llllllll}1 & 2 & 3 & 4 & 5 & 6 & 7\end{array}$

not at all

a great deal

5. Average pocket money you have each month (exclude basic living expenses): $\$$ 


\section{Appendix E}

\section{Demographics for Study 2}

1. Your Age:

2. Your gender: Male Female

3. Your cultural background (please specify) :

4. Please check a circle to indicate which of the following category best describes your family's annual income:

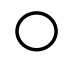

less than

$\$ 25,000$

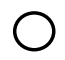

$\$ 25,000$ to

$\$ 49,999$

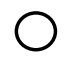

$\$ 50,000$ to

$\$ 74,999$
0

$\$ 75,000$ to

$\$ 100,000$
0

$\$ 100,000$ to

$\$ 124,999$

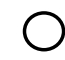

$\$ 125,000+$ 


\title{
Appendix F
}

\section{LETTER of INFORMATION \& COSENT To ACT as A HUMAN RESEARCH SUBJECT}

\author{
Ning Zhang, \& Dr. Li-Jun Ji \\ Department of Psychology, Queen's University
}

NAME OF PARTICIPANT (please print):

PURPOSE OF THE STUDY: This study is being conducted to explore how you make everyday purchase decisions. For this study, you will be asked to report your purchase decision with two options, write about the thoughts you have during the decision-making process, and complete several questionnaires. The study will take approximately 30 minutes to complete and you will receive .5 credit toward your course grade.

RISKS: There are no known physical, psychological, economic, or social risks associated with this study. Your participation in this procedure is completely voluntary and you may withdraw from this study at any time without any penalty. However, if answering any of the questions in this packet raises concerns for you or makes you uncomfortable, and/or if you would like to speak to a psychologist about a psychological or emotional issue, you may contact Health, Counseling, and Disability Services at 613533-2506.

BENEFITS: You will be awarded half a course credit for your participation. You will also have the opportunity to learn more about social psychology and research in general.

CONFIDENTIALITY: You understand that any information gathered from this study may be used in multiple analyses related to social and personality psychology, and that this information will remain entirely confidential and anonymous and will be stored in a locked cabinet in a secured building for the duration. You hereby authorize the use of all records and personal data derived from this experiment for these research purposes. You understand that any information derived from this research project that personality identifies me will not be voluntarily released or disclosed by the researchers without my separate consent, except as specifically required by law.

IF I HAVE QUESTIONS: Any questions about study participation may be directed to Ning Zhang at 613-533-6000 ext. 75617 or 0nz10@ queensu.ca. Any ethic concerns about the study may be directed to the Chair of the General Research Ethics Board at (613) 533-6081 or email Chair.GREB@ queensu.ca.

VOLUNTARY PARTICIPATION: By signing below, I indicated that I have read this Letter of Information \& Consent Form and understand the nature of this study. In addition, the experimenter has answered my questions satisfactorily. I know that I may refuse to answer any questions or discontinue my involvement at any time without penalty. My signature below indicates that I have read the information in this form and consent to participate in this study voluntarily.

Please keep a copy of this consent form for your record.

\section{SIGNATURE OF PARTICIPANT}

DATE

This study has been granted clearance according to the recommended principles of Canadian ethics guidelines, and Queen's policies. 


\section{Appendix G}

\section{Debriefing Letter}

This study is to explore potential cross-cultural differences in opportunity cost neglect (or consideration) in everyday purchase decision-making and the underlying mechanisms of this phenomenon.

We make a lot of choices in our everyday life. In most of the occasion, there are multiple options available for us, choosing one means giving up alternatives. This is the place where opportunity cost comes into play. Opportunity cost is typically defined as the "benefits foregone as a result of rejecting the best alternative option" (Becker, Ronen, \& Sorter, 1974). Logically, people should take opportunity cost into account in order to make rational and informed decisions, however, recent research with North Americans in accounting, economics, and marketing found that people generally neglect opportunity cost in decision-making. To our knowledge, little is known about when and why opportunity cost neglect happen for people from different cultural backgrounds. Based on previous research concerning cultural differences in thinking styles, we propose that East Asians and North Americans may differ in how and whether they consider opportunity cost in making decisions.

The results in this study will help us understand when and why opportunity cost happen in our everyday lives. If you would like to receive a copy of the results once data collection is finished, please contact Ning Zhang. We really appreciate your participation and hope that this has been an interesting experience for you. We would be appreciate it if you Do Not Reveal the Purpose of This Study to Others as this may bias their responses should they sign up for this study.

Any questions about study participation may be directed to Ning Zhang at 613-533-6000 ext. 75617 or 0nz10@queensu.ca. Any ethic concerns about the study may be directed to the Chair of the General Research Ethics Board at (613) 533-6081 or email Chair.GREB@queensu.ca.

Below is a reference to the present study if you are interested in knowing more:

Frederick, S., Novemsky, N., Wang, J., Dhar, R., \& Nowlis, S. (2009). Opportunity cost neglect. Journal of Consumer Research, 36(4), 553-561. doi:10.1086/599764

Thank you for your participation! Your interest in participating in this study is highly appreciated. 


\section{Appendix H}

\section{Letter of Clearance from GREB}

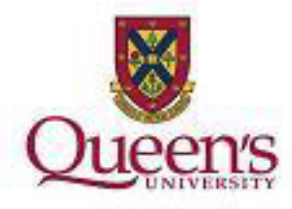

September 14, 2012 Mr. Ning Zhang, Master's Student

Department of Psychology Queen's University, Craine Building 31762 Arch Street

Kingston, ON K7L3N6 GREB Ref \#: GPSYC-576-12; Romeo \# 6007371 Title: "GPSYC-576-12 Cultural Differences in Opportunity Cost Neglect"

Dear Mr. Zhang: The General Research Ethics Board (GREB), by means of a delegated board review, has cleared your proposal entitled "GPSYC-576-12 Cultural Differences in Opportunity Cost Neglect" for ethical compliance with the Tri-Council Guidelines (TCPS) and Queen's ethics policies. In accordance with the Tri-Council Guidelines (article D.1.6) and Senate Terms of Reference (article G), your project has been cleared for one year. At the end of each year, the GREB will ask if your project has been completed and if not, what changes have occurred or will occur in the next year.

You are reminded of your obligation to advise the GREB, with a copy to your unit REB, of any adverse event(s) that occur during this one year period (access this form at https://eservices.queensu.ca/romeo_researcher/ and click Events - GREB Adverse Event Report). An adverse event includes, but is not limited to, a complaint, a change or unexpected event that alters the level of risk for the researcher or participants or situation that requires a substantial change in approach to a participant(s). You are also advised that all adverse events must be reported to the GREB within 48 hours.

You are also reminded that all changes that might affect human participants must be cleared by the GREB. For example you must report changes to the level of risk, applicant characteristics, and implementation of new procedures. To make an amendment, access the application at https://eservices.queensu.ca/romeo_researcher/ and click Events - GREB Amendment to Approved Study Form. These changes will automatically be sent to the Ethics Coordinator, Gail Irving, at the Office of Research Services or irvingg@queensu.ca for further review and clearance by the GREB or GREB Chair.

On behalf of the General Research Ethics Board, I wish you continued success in your research.

Yours sincerely,

Joan Stevenson, Ph.D, Professor and Chair, General Research Ethics Board

cc: Dr. Li-Jun Ji, Faculty Supervisor

Dr. Ye Li, Collaborator

Dr. Leandre Fabrigar, Chair, Unit REB

Marie Tooley, Dept. Admin. 